\title{
De lo político como nacimiento y modos de vida plurales en espacios asociativos
}

\author{
Pía Rius ${ }^{1}$
}

Fecha de recepción: 27 de julio de 2018

Fecha de aprobación: 05 de noviembre de 2018

\begin{abstract}
Resumen
En Argentina, a partir de los años 90, se multiplican los dispositivos de políticas sociales que tienen como protagonistas distintos espacios asociativos. En particular, en torno a programas de empleo que articulan distintas organizaciones de la sociedad civil, movimientos sociales y agrupaciones políticas que intentan apropiarse y redefinir esos dispositivos. Propongo aquí una reflexión que intenta echar luz sobre la experiencia de lo político en una población que irrumpe en la política nacional en la crisis de 2001 y hace de la autogestión un modo de vida alternativo. A partir de un trabajo etnográfico se dará cuenta de la manera en que lo político se ve anclado en lo cotidiano impregnando la organización colectiva, el trabajo, la alimentación o las producciones y consumos culturales. El trabajo de campo etnográfico permite cuestionar distinciones jerarquizadas entre movilizaciones políticas, sobre la base de reclamos universales y movilizaciones sectoriales desde intereses particulares para desplegar formas de involucramientos plurales. El artículo restituye distintas dimensiones del involucramiento que ponen en evidencia los efectos de compartir un lugar de encuentro, de eventos culturales, de trabajo y militante, en la búsqueda de una puesta en común políticamente informada, en particular por la reivindicación de la autogestión.
\end{abstract}

Palabras clave: autogestión, involucramiento, consumo, militantismo, modos de vida.

\section{On politics as a birth and plural lifestyles in associative spaces}

\begin{abstract}
Since the 1990s, Argentina has seen increased social policy devices with different associative spaces as protagonists; in particular, around employment programs articulated by different organizations of civil society, social movements and political groups trying to own and redefine these devices. This article proposes a reflection about the experience of politics in a population that
\end{abstract}

Doctora en sociología, Ecole des Hautes Etudes en Sciences Sociales (EHESS), París. Universidad de la Patagonia, Argentina. Contacto: piavrius@yahoo.com.ar 
breaks into national politics in the 2001 crisis and self-manages an alternative way of life. From an ethnographic work, it will describe how politics is anchored in everyday life impregnating the collective organization, work, food or cultural productions and consumption. Ethnographic fieldwork allows questioning hierarchical distinctions among political mobilizations based on universal claims and sector manifestations according to particular interests to deploy forms of plural involvement. The article restores different dimensions of involvement highlighting the effects of sharing a meeting place, cultural events, work and militancy in the search for a politically informed sharing, in particular for claiming self-management.

Keywords: Self-management - involving -consumption - militancy - ways of life.

\title{
Do político como nascimento e modos de vida plurais em espaços associativos
}

\begin{abstract}
Resumo
Na Argentina, a partir dos anos 1990 multiplicam-se os dispositivos de políticas sociais que têm como protagonistas diferentes espaços associativos. Em particular em torno dos programas de emprego que articulam diferentes organizações da sociedade civil, movimentos sociais e agrupações políticas que tentam apropriar-se e redefinir esses dispositivos. Proponho aqui uma reflexão que tenta lançar luz sobre a experiência do político em uma população que irrompe na política nacional na crise de 2001 e faz da autogestão um modo de vida alternativo. A partir de um trabalho etnográfico demonstrar-se-á a maneira em que o político se ve ancorado no cotidiano impregnando a organização coletiva, o trabalho, a alimentação ou as produções e consumos culturais. O trabalho de campo etnográfico permite questionar distinções hierarquizadas entre movilizações políticas com base em reclamos universais e movilizações sectoriais com base em interesses particulares para ampliar formas de envolvimentos plurais. $\mathrm{O}$ artigo restitui diferentes dimensões de envolvimento que põem em evidência os efeitos de compartilhar um lugar de encontro, de eventos culturais, de trabalho e militante na busca de uma partilha políticamente informada, em particular pela reivindicação da autogestão.
\end{abstract}

Palavras-chave: autogestão - envolvimento - consumo - militantismo - modos de vida.

En Argentina, a partir de los años 90, se multiplican los dispositivos de políticas sociales que tienen como protagonistas distintos espacios asociativos. En particular, en torno a programas de empleo que articulan distintas organizaciones de la sociedad civil, movimientos sociales y agrupaciones políticas, que intentan apropiarse y redefinir esos dispositivos. Propongo aquí una reflexión que intenta echar luz sobre la experiencia de lo político 
en una población que hace de la autogestión un modo de vida alternativo. A partir de un trabajo etnográfico, se informará acerca de la manera en que lo político se ve anclado en lo cotidiano, impregnando la organización colectiva, el trabajo, la alimentación o las producciones y consumos culturales. Los estudios centrados en lo político como una relación entre el Estado y la sociedad civil dejan de lado esta cotidianeidad en la que se toman decisiones éticas, estéticas, económicas y políticas. Aquí restituiremos estas dimensiones, que ponen en evidencia los efectos de compartir un lugar de encuentro, de eventos culturales, de trabajo y militante, en la búsqueda de una puesta en común políticamente informada, en particular por la reivindicación de la autogestión. En este sentido, distintos trabajos han puesto de manifiesto la vinculación entre la acción colectiva y las solidaridades territoriales (Svampa y Pereyra, 2004; Manzano, 2004; Merklen, 2005). Más específicamente, las perspectivas etnográficas abordan la manera en que distintos sujetos articulan lo político con distintas concepciones de trabajo, de lucha y de pertenencias locales (Quiros, 2011; Cross, 2014; Fernández Alvarez, 2016), así como la producción y utilización de un lenguaje característico de este espacio social (Cunha Comerfod, 1999; Cross 2010; Rius, 2010).

Conocí el surgimiento del Centro Social y Cultural (en adelante CSC) en el transcurso de la investigación de mi tesis doctoral. Desde su creación, el CSC se constituye como lugar de realización de distintas actividades de movimientos de trabajadores desocupados y de agrupaciones estudiantiles, culturales y políticas. Esa entrada me facilitó el acceso para mi investigación posdoctoral realizada en 2013 y 2014, en dos estadías de un mes cada una, en el marco del proyecto colectivo de investigación ANR PORQUE². En agosto de 2013 tomé contacto con distintas coope-

2 La tesis doctoral (2010) restituye el surgimiento y la continuidad de distintas organizaciones de trabajadores desocupados y el entorno en y con el que se constituyen. El proyecto es financiado por la Agencia Nacional de Investigación de Francia ANR sobre las Prácticas y Organizaciones en Barrios Populares -PORQUE- en el seno del laboratorio Clersé/CNRS de la Universidad de Lille 1. Así pude acompañar la vida 
rativas de trabajo y de consumo, funcionando en el CSC situado en la ciudad de La Plata, capital de la Provincia de Buenos Aires, en un barrio de la ciudad próximo al centro político y administrativo. Las observaciones se realizaron compartiendo los lugares de trabajo de distintas actividades (principalmente la cooperativa de consumo, la cocina, la portería y el taller textil; también acompañé a los miembros de estos espacios fuera de la actividad de trabajo, a sus domicilios y en movilizaciones y trayectos urbanos, y participé de las actividades culturales propuestas en el espacio). El espacio "multisectorial" se ve atravesado por las tensiones propias de la participación en distintos dispositivos de políticas gubernamentales (Programa "Argentina Trabaja", Programa de Trabajo por Autogestión, Programa Universitario de voluntariado, entre otros), la búsqueda de la autogestión como horizonte político y, en el nivel local, desarrolla una crítica de la política cultural y urbana de la ciudad que resulta en la segregación de los sectores populares, pero también se vincula con el trabajo doméstico y la búsqueda de modos de vida acordes con esas decisiones.

Desde una perspectiva de cogestión, el diseño de las políticas sociales y de empleo abre un amplio espectro de posibilidades para redefinir relaciones en el espacio social en que se incertan los propios dispositivos. Las autoridades intentan, con mayor o menor éxito, moldearlo y canalizarlo ${ }^{3}$. Sin embargo, esa perspectiva deja de lado los procesos de construcción de lo común que entrelazan y desbordan la mera gestión de los recursos públicos. El artículo propone iluminar esa tensión a la luz de los modos de

cotidiana de las personas involucradas en distintas actividades realizadas en el CSC, y a algunas de ellas acompañarlas en su cotidianeidad fuera de ese espacio, a partir de una metodología etnográfica, teniendo en cuenta las temporalidades propias y las trayectorias familiares. Los nombres de las personas citadas son ficticios.

3 Desde la conformación del Estado argentino, el medio asociativo aparece como un modo de gestión de la política social (Di Stefano et al., 2002). A partir de las reformas neoliberales de los años 90 , ese recurso es promovido por los organismos de crédito internacionales, como el Banco Mundial o el FMI, que lo presentan como una manera de intervención social más eficaz que la estatal. 
vida que redefinen las distinciones entre el mundo del trabajo, de la militancia y de la solidaridad. En efecto, en ese espacio social se observa la manera en que se cruzan y coexisten numerosas figuras y actividades, que desafían las distinciones ordinarias de lo que acontece en tanto compromiso político, de trabajo como actividad para ganarse la vida, la obra artística o cubrir las necesidades materiales. Resulta pertinente retomar la concepción arendtiana de la acción en su reflexión sobre la condición del hombre moderno, en la medida en que lo político es un nuevo comenzar que se constituye en oposición al trabajo repetitivo y a la obra como transformación del ambiente humano (Arendt, 1983). Bajo el prisma de la autogestión, las nociones y prácticas se redefinen mutuamente. La división del trabajo impone la rotación de las actividades, proponiendo no producir especialistas de la toma de decisión y la representación como arte separado de la actividad; de esa manera, se habilita un cuestionamiento a la división taxativa entre militantes y trabajadores, pero también entre varones y mujeres (el conjunto de los espacios observados son mixtos); ello introduce en la gestión del tiempo de trabajo un tiempo compartido y con "compañeros".

El análisis permite poner en evidencia un continuo que recorre el arte de vivir, actividad profesional y militancia característica de las formas de involucramiento señalados en el transcurso de la investigación, en la cual la experiencia releva una manera de "habitar" el CSC ${ }^{4}$ En el desarrollo del proceso de investigación precedente, he podido observar de cerca interacciones entre usuarios en este centro social y cultural, y la manera en que los intercambios se apoyan en el medio asociativo a partir de dife-

Las ciencias sociales suelen otorgar a los derechos civiles y políticos mayor jerarquía que a los derechos sociales. El término "habitar", señalado por los propios actores, ofrece el potencial para superar esas falsas dicotomías. Marc Breviglieri y Luca Pattaroni (2005) se refieren a las maneras de «habitar» un squat, como una forma de militantismo mínimo que se reduce a los eventos festivos. En el CSC parece evocado en un sentido amplio, ya que al momento del trabajo no hay personas viviendo allí. 
rentes figuras: trabajadores, estudiantes, militantes, compañeros del barrio, vecinos. El trabajo etnográfico resulta propicio para capturar una temporalidad en la que la cotidianeidad revela las huellas de acuerdos y tensiones.

El proceso de involucramiento en el seno del CSC aparece puntuado por momentos de evaluación en la interacción entre miembros o en el transcurso de las entrevistas ${ }^{5}$. A través de esos intercambios se intenta construir una manera de vivir juntos, una coordinación dada por momentos de convivialidad, de luchas compartidas, así como de tensiones y disputas que se hacen explícitas durante las asambleas. Antes de abordar estas cuestiones conviene restituir en un primer paso el momento histórico en el cual se inscriben ese modo de vida y esa relación con lo político. Luego, a partir de la etnografía y del análisis de las interacciones en ese medio, cuestionaré la manera en la cual convergen en un mismo espacio las poblaciones heterogéneas que se involucran en el CSC en función de sus trayectorias, expectativas y posibilidades efectivamente realizadas.

\section{Un centro social y cultural creado al comienzo de los años 2000. Una metáfora del nacimiento}

El año 2001 representa una ruptura generacional. Me siento parte de esa generación que buscó democratizar el debate, redefinir el Estado (Héctor, 34 años, entrevista realizada en el CSC, agosto 2014).

La creación de CSC se inscribe en un proceso de movilización de alcance nacional a comienzos de 2000, que involucra a gremios, sindicatos, empresas recuperadas, colectivos de des-

\footnotetext{
5 Las entrevistas registradas surgen a lo largo del proceso de observación. Se realizaron una veintena de entrevistas en profundidad, la mayor parte en el espacio mismo del CSC, pero fuera de los horarios de trabajo, buscando capturar distintos recorridos biográficos y de la organización.
} 
ocupados, asambleas de vecinos que, en mayor o menor medida, también están presentes en los inicios del CSC. Variadas actividades contestatarias muestran la actualización de repertorios de acción colectiva que abrevan en tradiciones obreras, como el corte de ruta en tanto expresión de los trabajadores en un piquete; como las asociaciones y agrupaciones vecinalistas, con sus organizaciones barriales; como el movimiento de derechos humanos, protagonista desde el regreso de la democracia ${ }^{6}$. Para algunos miembros del CSC, estos procesos marcaban la ruptura que los ha proyectado en la primera plana de la escena política. En efecto, el fin del gobierno de De la Rúa, en diciembre de 2001, con miles de argentinos en las calles al grito de "que se vayan todos" y desafiando el llamado a estado de sitio del gobierno, es reconocido como un momento de quiebre en la historia reciente, que daría cuenta de la fuerza de la presencia de la ciudadanía en las calles. En los momentos de mayor movilización en la vía pública, la presencia de la población en las calles parecía indicar cambios profundos en la matriz argentina de relaciones políticas y sociales. Con el paso del tiempo, las interpretaciones son más moderadas; sin embargo, la fecha sintetiza simbólicamente las posibilidades de expresión y de organización desarrolladas por distintos grupos, la capacidad de rechazar medidas consideradas autoritarias y particularmente contrarias a las consecuencias de las políticas de liberalización de la economía, de "reforma estructural del Estado", y las consecuencias sociales de esas reformas: aumento exponencial de la desocupación, de la pobreza, de la indigencia, la fragmentación de la clase media argentina y un incremento de la polarización social (Svampa, 2000).

La historia de las organizaciones de derechos humanos en Argentina está fuertemente marcada por la lucha contra la última dictadura cívico-militar (19761983). Más recientemente, sobresale la exigencia de justicia por los detenidos y detenidos-desaparecidos, así como por sus hijos apropiados. Una importante red de asociaciones se ha creado en torno a familiares y organizaciones de asistencia jurídica y política a las víctimas de violaciones de los derechos humanos en un sentido amplio (CELS, Servicio paz y justicia - SERPAJ, CORREPI, entre otras). 
2001 opera para esta generación como una metáfora del nacimiento a la vida política en la cual inscribirse. En el CSC, la referencia al 2001 articula cierta desconfianza hacia la democracia representativa en la búsqueda de un "cambio social" o de la "organización popular". También se expresa en el involucramiento en la acción "territorial", en el rechazo a participar en los procesos electorales y en la necesidad de constituir una nueva forma de vida política. La perspectiva etnográfica recupera las acepciones de los actores (Rosato y Balbi, 2003) y permite precisar los involucramientos plurales que vuelven el espacio del CSC a la vez personal y común a quienes lo habitan, lo pintan, organizan sus almuerzos, aprenden a cocinar y militan en organizaciones culturales y políticas a partir de formas de familiaridad que se tornan políticas en sus efectos (Thévenot, 2016). Para la generación de Héctor, un joven que entonces transitaba los primeros años de sus estudios universitarios, señala un corte en ese momento histórico, un antes y un después en la vida política nacional. En su caso particular también implica una ruptura en la propia trayectoria, ya que interrumpe sus estudios en Ciencia Política para dedicarse a la militancia barrial territorial. Esa ruptura, formulada como un nuevo comienzo, envuelve su propia trayectoria personal, a los 21 años, y la de su generación en un sentido amplio de quienes acceden a la escena política en esa irrupción.

En enero de 2002, la elección como presidente por el Senado del exgobernador de la provincia de Buenos Aires, por entonces senador Eduardo Duhalde, para finalizar el mandato de De la Rúa, se acompaña de un proceso considerado de normalización de la política. Entendido como un mayor control de las movilizaciones callejeras, se traduce en una escalada de represión lanzada contra las organizaciones de trabajadores desocupados o piqueteras. En junio de ese mismo año la represión termina con la vida de dos jóvenes manifestantes en manos de las fuerzas represivas, lo que relanza las movilizaciones masivas. Eduardo Duhalde no finaliza el mandato y se ve en la obligación de anticipar las elecciones presidenciales. Nestor Kirchner es elegido con 22\% de 
los votos en mayo de 2003, luego de la decisión del expresidente Carlos Menem de no presentarse a la segunda vuelta. En los primeros meses realiza una serie de gestos simbólicos hacia las organizaciones de defensa de los derechos humanos y hacia las organizaciones piqueteras que acceden a la Casa Rosada, simbolizando procesos de redefinición de la dimensión contestataria de esas organizaciones y la apertura de distintos procesos de articulación política.

A pesar de las críticas, que señalan la profundización de la precariedad laboral por parte del Estado, la economía social aparece en esos momentos de crisis como una solución posible al desempleo de masa. El gobierno sostiene, por ejemplo, el lanzamiento de diversos programas de financiamiento público de proyectos cooperativistas. Desde 2003, las experiencias de cooperativismo conocen un desarrollo creciente. El Instituto Nacional de Economía Social, INAES, registraba 193 cooperativas en 1990, de las cuales 98 eran cooperativas de trabajo. En 2005 la cantidad asciende a 2.428 incluyendo 1.962 cooperativas de trabajo. Este auge articula diferentes procesos: por un lado, el desarrollo de iniciativas de autogestión, impulsadas en el marco de movilizaciones sociales en torno a la demanda de trabajo, ya por la formación de cooperativas a partir de la recuperación de fábricas, así como por experiencias asociativas desarrolladas por las organizaciones de trabajadores desocupados; por otro lado, la implementación a partir de 2003 de una serie de medidas políticas apoyadas en la lógica de la economía social y el desarrollo local, que ha permitido el desarrollo del autoempleo y del trabajo asociativo para las poblaciones consideradas "vulnerables". El CSC en particular, bajo el esquema formal de una cooperativa con finalidades múltiples, alberga en esa etapa más de una docena de proyectos sociales y productivos que, a su vez, se vinculan entre sí y con otros espacios territoriales.

En el CSC, organizado en torno a la autogestión, quienes se pliegan abiertamente a esas políticas sociales son designados como "funcionarios entre comillas", una imagen que señala a 
ciertos dirigentes sociales por asumir posiciones en la gestión gubernamental de los programas orientados al sector sin llegar a serlo realmente. En esta valoración, el cuestionamiento refiere tanto al acercamiento entre los dirigentes y las autoridades como a la fragilidad de los espacios obtenidos mediante la construcción política partidaria tradicional. En este caso, las comillas indican la ficción de esa integración, que adolece de los derechos reclamados en estos espacios en una suerte de representación ad hoc incompleta. La necesidad de tomar distancia de los partidos políticos tradicionales y de las organizaciones que se han vinculado al gobierno nacional se traduce en diferentes formas de organización local, de reclamar lo que se considera como un derecho, que los militantes designan como "construcción de poder popular". Esa consigna no tiene un sentido unívoco, como lo señalan varios análisis que la inscriben en la historia de las tradiciones políticas latinoamericanas (Mazeo, 2007; Gaudichaud, 2012), o la sintetizan con el término de "empoderamiento"7. Los vínculos con las autoridades locales y nacionales son designados aquí bajo la forma de un combate permanente, "una lucha", y como un reclamo de acceso y goce de derecho. Un derecho a hacer valer, más allá de la voluntad de los "funcionarios entre comillas", procedentes de distintas organizaciones territoriales. La disputa por los recursos se ve imbuida de una dimensión moral, a partir de la presencia en el territorio y del rechazo a la desigualdad de tratamiento de algunos sectores marginalizados o de sus propias organizaciones en distintos barrios. En su dimensión cotidiana, se hacen presentes los riesgos de cooptación que el grupo intenta sortear de distintas maneras: rotando los portavoces, gestionando los proyectos colectivamente y organizando redes y encuentros entre distintos proyectos para establecer pautas comunes de funcionamiento. La versión extrema de esa tensión se expresa en

\footnotetext{
El término no es utilizado ampliamente si no puntualmente, y también con cierta distanciación, utilizando la expresión "entre comillas", realizando el gesto de las comillas con las manos, o bien señalando que es un término ajeno al referirse a lo que otros designan como "empoderamiento".
} 
el abandono de ciertos miembros que se unen a otras organizaciones.

Esa distancia de los partidos políticos lleva, en un primer tiempo, a un rechazo de la democracia representativa y de la participación electoral. En efecto, esas organizaciones populares, como muchos de los movimientos de trabajadores desocupados, desde su creación rechazan participar de las elecciones, ya sea presentando un candidato propio $\mathrm{u}$ orientando el voto de sus miembros hacia los candidatos partidarios. Aun así, a cada instancia electoral, la pregunta sobre quiénes son los candidatos y a quién conviene votar subsiste. Alguna de las respuestas que ofrecen estas organizaciones locales consiste en analizar los distintos candidatos, estudiar y difundir quiénes son, en términos de trayectoria local, sus antecedentes de gestión, etc., comparando distintas propuestas defendidas, sin perjuicio de llamar a no votar. En 2013, las agrupaciones reunidas en un Frente Nacional Multisectorial debaten una vez más la necesidad de participar en las elecciones con candidatos propios a nivel local. En la región de La Plata deciden participar en las elecciones locales. En consecuencia, tanto los estudiantes militantes en organizaciones universitarias como los "compañeros de los barrios" se vuelcan de lleno a la campaña electoral. Sin embargo, la participación electoral, tal como es aceptada aquí, queda supeditada al desarrollo de las organizaciones sociales que componen el colectivo. Uno de los jóvenes militantes me explica, en uno de nuestros primeros encuentros, que el movimiento político está sujeto a la voluntad de la asamblea. Esa decisión pone de relieve la modalidad de "construcción de poder popular" que se proponen desarrollar. No siempre se alcanza esa subordinación de lo partidario a otras formas de construcción colectiva; aun así los miembros de las distintas cooperativas se refieren a "nuestro candidato", participan de los actos públicos y manifestaciones realizadas en esa contienda electoral, las internas abiertas simultáneas y obligatorias PASO. En el Frente la decisión no es compartida en todas las localidades, se produce una ruptura en el seno del movimiento y da origen a una nueva coordinación, que decide participar del 
proceso electoral en distintas localidades donde se hace presente (Frente Popular Darío Santillán Corriente Nacional). Esta dinámica da cuenta de la necesidad de revisar las conceptualizaciones que jerarquizan el reconocimiento de "derechos ciudadanos" por encima de las movilizaciones que se orientarían en defensa de "intereses particulares", a fin de dar lugar a expresiones de lo político acordes con estas prácticas que se registran etnográficamente.

\section{La autogestión: una forma de presencia corporal y un sentido de la actividad}

Los jóvenes se reconocen parte de una generación que alcanza la escena nacional en 2001. En la escena local, la ocupación del edificio donde funciona actualmente el CSC data también de esa época. A los diez años de ocupación, al momento de comenzar el trabajo de campo (2013), se realiza una campaña por la expropiación definitiva. En efecto, el local, edificio de una escuela abandonada, ha sido objeto de una ocupación por un conjunto de organizaciones territoriales y estudiantiles. A la vez que se han instalado para evitar su evacuación de fuerza, continuamente han trabajado para poder realizar más actividades, mejorar el edificio y expresarse en los sucesivos murales realizados en el frente y en los patios. Este proceso no es singular, sino que caracteriza un conjunto de centros sociales y culturales que se organizan mediante la autogestión. Aquí analizamos este término desde los usos de los propios actores como expresión de oposición a las formas y circuitos institucionalizados de la cultura. Los centros culturales enfrentan distintas formas de sanción municipal o provincial, que van desde multas hasta la clausura parcial o total de los espacios; por ello, generan acciones frente a la legislatura provincial y consejos deliberantes que serán articulados posteriormente en distintas redes ${ }^{8}$.

\footnotetext{
8 Red de Espacios Culturales, la Ronda de Espacios Culturales Autogestivos, Unión de Centros Culturales Alternativos y Artistas de La Plata.
} 
La presencia en el lugar y el trabajo por asamblea devienen el elemento central para asegurar la continuidad de sus acciones. Esa modalidad los acerca a la experiencia de las organizaciones de trabajadores desocupados, piqueteras, que forman parte de esta multisectorial, así como a las ocupaciones de tierras en la periferia de la ciudad 9 .

A medida que se realizan diferentes trabajos de construcción ${ }^{10}$ y mantenimiento, el espacio se vuelve habitable no solo para asegurar la presencia, si no para desarrollar actividades económicas (proyectos productivos, talleres), culturales (presentación de libros, espectáculos musicales) y políticas (organización de manifestaciones, lugar de encuentro de militantes, etc.). De hecho, luego de la ocupación, varios proyectos que se estaban lanzando en barrios periféricos, en el seno de organizaciones de desocupados (pizzería, taller textil, cría de gallinas), se desplazan hacia el local, ubicado cerca del centro, donde en algunos casos se encuentra mayor lugar e infraestructura disponibles y, a su vez, contribuyen con su presencia a la estabilización de la ocupación. También aportan con formas de trabajo autogestivo, contribuyendo en jornadas colaborativas a recolectar fondos o a realizar los trabajos de albañilería, electricidad, pintura etc. que requieren las obras. Cuando esos proyectos y actividades obtienen financiamiento gubernamental, una parte de los recursos se consagra al trabajo edilicio, un mejoramiento que se torna constante y permite la utilización de nuevos espacios o la intervención artística de distintas paredes que exhiben murales propios de las actividades desarrolladas ${ }^{11}$.

\footnotetext{
9 Las investigaciones de Merklen (2005) indagan sobre la toma de tierras y asentamientos en barrios de La Matanza, con una politicidad basada en la búsqueda de la legitimidad de los barrios en oposición a las villas.

10 Uno de los proyectos pendientes es la posibilidad de completar la instalación de gas, lo que permitiría un mejor desarrollo de los trabajos en invierno y de las actividades de cocina.

11 En 2014 amplían el uso de salones del primer piso para implementar nuevos cursos y actividades abiertas.
} 
La amplitud de los trabajos necesarios para poner en funcionamiento el local requirió que algunos miembros fueran mandatados por la asamblea del CSC para ocuparse de los trabajos de infraestructura (instalación de electricidad, reparación de techos, etc.), en función de sus habilidades y posibilidades. A partir de 2008 ese trabajo es realizado más ampliamente, para permitir la apertura de talleres y actividades en vinculación con el barrio donde está implantado. El mandato de apertura no era nuevo pero adquirió mayor importancia. Esa actividad se enmarca en la idea de autogestión que conciben en el grupo: tienen objetivos comunes; para retomar los términos de uno de los miembros del grupo de portería, la actividad "tiene un sentido": ser acogedor ante un público diverso que no se agota en los compañeros de las organizaciones que están en la red, sino también se dirige a vecinas y vecinos a los cuales hay que explicar el funcionamiento por asamblea. En el local donde se encuentra la portería los encargados reciben a los vecinos, a menudo en torno a un mate, manteniendo y verificando la información actualizada en internet, informando de los horarios de los nuevos talleres, y dando a conocer las particularidades del espacio: no se trata solo de un salón en el que tomar o dar clases, o de organizar una actividad entre vecinos: el CSC ofrece la posibilidad de participar en el órgano de decisión, de realizar cursos en forma económica, por debajo de los precios del barrio, o gratuita si una familia no puede pagarlos, o la posibilidad de proponer actividades nuevas siempre que se retome la modalidad de funcionamiento autogestivo. Esta dimensión de la autogestión refiere a la relación con los talleristas, que no son empleados ni inquilinos, y entre vecinos.

Así, la cantidad de talleres ofrecidos se amplía, incorporando nuevas propuestas ofrecidas por los miembros de los talleres productivos, que incluyen enseñanza de oficios, herrería, textil, o, en forma puntual, de cocina latinoamericana, o de alimentación consciente, abiertos a los habitantes del barrio y de la ciudad en general. 
Presentar el CSC solo teniendo en cuenta las actividades culturales sería reductor, dejaría de lado el centro como espacio de producción de las cooperativas presentes, o a la modalidad de ocupación espacial. Una síntesis de la rutina de las jornadas en el CSC permite señalar los intercambios y conexiones entre aquellas actividades habitualmente señaladas como trabajo, militancia o vecinazgo: aquí la manera alternativa de definir esas actividades permite observar prácticas que son mutuamente redefinidas, oponiendo no solo trabajo y no trabajo en términos de producción y ocio, sino articulando distintas formas de producción consideradas o pretendidas legítimas, que hacen visibles los regímenes de involucramiento ${ }^{12}$ en los momentos de tensión y convocan la necesidad de reflexión de y entre los distintos miembros.

En 2013 la jornada comienza antes de las 8.00 AM con la radio comunitaria que funciona en el primer piso, en un amplio estudio cuyos programas se propagan por internet. Los responsables del programa matinal comienzan a las 8.00 horas, llegan en el mismo horario que quienes participan del taller textil. Ambos grupos tienen llave y cierran la puerta de hierro una vez que ingresan, ya que no hay demasiado movimiento en esa franja horaria. Cada grupo trabaja en sus respectivos lugares y los espacios comunes permanecen silenciosos y vacantes. Los miembros de portería $^{13}$-en forma rotativa- abren el CSC a las 9.00 horas. A

12 Retomamos aquí la noción de "involucramiento" señalada por Thévenot (2016), que tiene en cuenta no solo la dimensión discursiva, sino la ocupación corporal del espacio y las tensiones que puede generar en tanto involucra la relación del actor con su entorno, limitaciones que este impone y las potencialidades que genera.

13 La portería es un grupo compuesto de seis a ocho jóvenes en ese momento, varones y mujeres de entre 20 y 35 años de edad. Su actividad consiste en realizar tareas de mantenimiento, control de apertura y cierre de la puerta de entrada y actualización de la información de cartelera. Realizan un total de entre 20 y 30 horas de trabajo cada uno. El pago se realiza a partir de los fondos recaudados en fiestas realizadas en el CSC y de programas de apoyo a la economía social. Además del mantenimiento de los espacios comunes (patios, pasillos, baños de planta baja), el grupo maneja las actualidades para difundir la agenda por internet, así como la fiesta mensual de varieté un sábado al mes que les permite recaudar fondos. El local de la portería está situado en el pasillo, entre los dos patios, y suele servir de lugar 
partir de entonces el local queda accesible con la puerta sin llave durante todo el día y comienzan a llegar los miembros de los distintos talleres. La autogestión del local recae en muchos aspectos en el grupo de portería; sus miembros realizan turnos de entre 20 y 30 horas semanales. Su presencia en el local es cotidiana y a lo largo de toda la jornada hasta las 24.00 horas. Los talleres que funcionan por la mañana (aparte de los ya mencionados), como el de herrería, el de electricidad y dos productivos de imprenta están presentes entre las 9.00 y las 15.00 horas. Aquí también la presencia de los distintos trabajadores es flexible en función de los horarios acordados al interior de cada grupo. En el trabajo de campo solicité, en las asambleas de cada grupo, participar en distintos talleres que se desarrollan en distintos momentos, experimentando diversos ambientes generados en los talleres.

A lo largo de la jornada se escuchan los ruidos de las máquinas, una radio en el productivo de cocina, los distintos trabajadores que se cruzan y comparten el espacio común del patio, en el que a veces se juntan a comer y compartir un momento de encuentro. A partir de las 11.30 horas el productivo de cocina recibe los primeros pedidos de los comercios y oficinas de las zonas cercanas; además, preparan viandas para un comedor universitario. Al mediodía, cuando se retiran las trabajadoras del taller textil, saludan e intercambian con los miembros del taller de cocina, el sector de mayor movimiento. En el patio se estaciona una moto que uno de los miembros del grupo utiliza en el reparto ${ }^{14}$. Distintos comensales llegan a almorzar. Algunos se manejan en el lugar con cierta familiaridad. Es un horario de reunión para las organizaciones estudiantiles, políticas y movimientos sociales que consideran el CSC un punto de encuentro y un local propio. En las mesas recientemente pintadas, dispuestas en el patio de-

de recepción de consultas del público, de algún compañero buscando a alguien o simplemente solicitar la PC para revisar rápidamente una información personal.

14 El vehículo ha sido adquirido gracias a un crédito de un fondo cooperativo establecido entre las organizaciones miembros del frente regional FPDS-CN. 
lantero, se conversa, se preparan volantes y acciones de campaña propias de ese año electoral, en el que participan por primera vez de los comicios con un joven candidato a intendente. La campaña impregna la cotidianeidad del CSC durante el mes de agosto en que se realiza el trabajo de campo. Es frecuente cruzar los militantes en pequeños grupos y al candidato a intendente, un joven de poco más de 30 años. Los trabajadores de los distintos talleres se refieren a la campaña y al avance de "nuestro candidato". En los actos públicos confluyen buena parte de los participantes de los distintos talleres y espacios. El cierre de campaña es aún más convocante. Distintos participantes de las actividades del CSC están presentes en el acto y ovacionan cuando el candidato señala su propuesta como popular y feminista. El domingo del recuento de votos el CSC se transforma en espacio de festejo del buen resultado de la interna en donde se impuso su candidato ${ }^{15}$.

Por la tarde se desarrollan la mayoría de las actividades culturales abiertas al público: guitarra, percusión, flauta traversa, tango, salsa, danza contemporánea, afro-danza, bio-danza, teatro, folclore, biblioteca popular, entre otros. Los participantes parecen tener el mismo perfil que los organizadores, con una importante presencia de jóvenes estudiantes universitarios, pero también de "compañeros del barrio", muchos de los cuales tienen menos años de estudio, experiencia política territorial y han participado en organizaciones de desocupados. Es un momento de creciente afluencia, ya que los talleres se abren a las personas que vienen por su interés por una actividad elegida. Aquí mi presencia se dio en tanto participante de la actividad sin precisar más requisito que la inscripción. Los vecinos que llegan a inscribirse son recibidos en la portería y puestos inmediatamente en contacto con los encargados de cada actividad.

15 En el marco de las elecciones Primarias Abiertas Simultáneas y Obligatorias, PASO, se constituye un frente de izquierda para elegir un candidato común. Para que el candidato sea elegible en la elección general es necesario alcanzar 1,5\% de los votos en las PASO, de lo contrario la formación política puede ser eliminada. 
Los encargados de la portería aclaran que, en caso de dificultades económicas, hay becas para facilitar la participación de los interesados. Uno de ellos me recalcó que, al no ser el modo habitual de funcionamiento en otros espacios, lo aclaran siempre que llega una nueva persona a consultar. Además de los talleres, también funciona una cooperativa de consumo y el restaurante, que concentra gran parte de la afluencia del público de ese horario del jueves al sábado ${ }^{16}$. Los jóvenes trabajadores de la cocina tienen la responsabilidad de cerrar el CSC cuando trabajan hasta tarde, excediendo el horario de trabajo de la portería que, conforme a los acuerdos alcanzados en la asamblea del CSC, permanecen hasta medianoche.

También se realizan reuniones de distintos grupos culturales o de involucrados en diferentes movimientos en las salas disponibles o en los patios, como las del grupo de arte callejero, las de hombres antipatriarcales, de autogestión, de administración de proyectos (que gestionan la financiación de las autoridades) o las asambleas regionales del FPDS. La autogestión del tiempo y del espacio muestra cierta flexibilidad en relación a las personas que pueden tomar responsabilidades. Así, en función de las disponibilidades de la presencia o no en los lugares en los momentos de apertura y cierre, o de la necesidad de horarios especiales para ciertas actividades, la gestión de los accesos a los locales es compartida por los miembros de diferentes talleres a través del mecanismo asambleario. En esa rutina, el trabajo etnográfico se hace más o menos visible según el tipo de involucramiento solicitado, requerido o acordado con quienes participan en la gestión.

\footnotetext{
16 En el periodo de estudio el proyecto de cocina se encuentra en transformación, ya que se intenta coordinar con el grupo de la noche. El grupo del mediodía realiza una cocina variada y cuenta con varios participantes que tienen formación o experiencia en el oficio, mientras que el grupo de la noche originalmente surgió como una pizzería, a cargo de distintos compañeros del barrio que aprendieron el arte de la cocina en el transcurso de esa experiencia.
} 


\section{Autogestión y remuneración}

El trabajo en voluntariado ha sido analizado mostrando las tensiones que pueden aparecer en torno a las condiciones de trabajo y su reconocimiento económico como tal (Simonet, 2003; Hély, 2009). La actividad en el mundo asociativo suele ofrecer a los participantes la posibilidad de elegir el sector de la organización en que se van a desarrollar, los horarios, el tiempo del que disponen, etc. Sin embargo, el trabajo no es remunerado o su remuneración es escasa. Eso lleva a la dificultad de considerar el mundo asociativo como un espacio laboral propiamente dicho (Hély, 2009).

En el caso del CSC, las actividades productivas y organizativas realizadas en torno a los distintos espacios son reivindicadas como un trabajo pero no como un empleo. La organización en autogestión es colectiva, orientada a la forma cooperativa, aunque no todos los talleres alcanzan a formalizarse en esta figura jurídica. La autogestión aparece como una apuesta con el propósito de producir formas de trabajo alternativas en las cuales la autogestión está en el corazón de una forma de vida alternativa. La flexibilidad en los horarios en relación a la apertura y cierre del local y las obligaciones que eso puede generar para quienes trabajan en la portería permite captar una forma de adaptación, con flexibilidad en la organización del trabajo, decidiendo colectivamente cómo resolver las distintas tensiones. En algunos productivos se resuelve dividir las tareas, de manera que puedan ser realizadas en forma colaborativa, teniendo en cuenta no solo la necesidad de producir determinado bien o responder a un pedido, sino también la trayectoria y la situación personal de la persona que se establece en un determinado puesto de trabajo. Distintas formas de la autogestión permiten formar parte de la definición del trabajo "sin patrón".

El tiempo consagrado a la autogestión es en parte remunerado, aun cuando puede haber distintos criterios en función de los acuerdos que logran los miembros de los productivos y de 
cada asamblea en la que se definen las reglas. Por ejemplo, en el caso del taller de costura hay un horario de trabajo común por la mañana y la asamblea se desarrolla dentro del horario de trabajo. Las compras o gestiones en las oficinas gubernamentales cuentan como hora trabajada y la capacitación de nuevas compañeras también. Estos acuerdos se logran, a pesar de las tensiones que implica incluir distintas actividades y reducir el alcance de la productividad como criterio preponderante para establecer la remuneración (Rius, 2017). El tema de la remuneración es objeto específico de la indagación, pero sobre todo es un eje de discusión entre los mismos trabajadores, que buscan hacer de estas actividades sus principales fuentes de ingresos.

En el caso de la portería sucede algo similar, las actividades de organización se desarrollan durante el horario de trabajo. Las asambleas requieren la presencia de todos los miembros del productivo y, dado que se trata de turnos rotativos, la mayoría de los miembros está fuera de su horario habitual a la hora de participar de la asamblea; entonces, participar del órgano decisorio se considera como un gesto militante y de transmisión de experiencia hacia los nuevos integrantes del grupo. Por otra parte, estas reuniones no son tan frecuentes ni regulares, y son convocadas puntualmente para resolver distintos aspectos de la actividad.

En la portería, en la medida en que el volumen de trabajo se incrementa se van incorporando nuevas personas. El aumento de ingresos para cada miembro es poco probable y no siempre se expresa como un objetivo a alcanzar. Más bien se busca cierto equilibrio en la distribución de las horas entre los trabajadores. Una situación diferente se observa en la cooperativa de consumo, en la que aparece un elemento suplementario: la imposibilidad de contar en forma sostenida con programas estatales que garanticen una parte de los ingresos. En la cooperativa textil, el objetivo explícito de desarrollar la actividad para generar mayores ingresos para sus trabajadoras repercute en la imposibilidad de acceso de nuevos integrantes. Otra respuesta ante esta tensión se da en el grupo de cocina, en el que se desarrollan nuevas actividades 
con modalidad autogestiva para incrementar los ingresos. Es el caso de los talleres de cocina latinoamericana, que se realizan en horarios en que las instalaciones quedan disponibles y solo participa una parte de los miembros.

Los trabajadores de portería, que suelen permanecer en el CSC para participar en distintos talleres fuera del horario de trabajo, pueden ser interpelados por cuestiones relativas a la portería (horarios o lugares de reunión, actividades corrientes, etc.). En varias oportunidades vimos al portero señalar que no está en el horario de portería. Podríamos ver en ese gesto la dificultad de tener un tiempo personal. En las escenas observadas el argumento parece aceptarse, ya que no se insiste, aun si la confusión del tiempo de trabajo y el tiempo de participar a un taller da cuenta de la manera en que el trabajo en ese espacio asociativo desborda una distinción rígida entre trabajo y no trabajo. En particular en la portería esto se observa con más insistencia, ya que permite realizar actividades militantes (organizar una acción callejera, diseñar afiches para una actividad, pintar banderas) en el horario de trabajo.

En la sala conjunta a la portería funciona una cooperativa de consumo, un almacén que ofrece productos de pequeños productores de la zona con el objetivo de acercar productores y consumidores. El horario de apertura de la atención al público es por la tarde. En ese momento se concentran tanto la recepción de productores, generalmente semanal, como la venta al público. La asamblea y una serie de actividades propias del funcionamiento son realizadas fuera del horario de apertura y no son remuneradas. Si bien la asamblea acuerda con esa postura, a medida que ciertas actividades requieren mayor dedicación, como la preparación y fraccionamiento de productos y la organización del stock, en distintas etapas de desarrollo del productivo se incluye una remuneración, teniendo en cuenta la carga horaria. En todos los talleres y espacios productivos observados el criterio de remuneración se calcula a partir de la relación entre ingresos generados en el productivo y la cantidad de horas trabajadas por 
cada persona. Como resultado, los ingresos son variables mes a mes, según los horarios establecidos y el grado de desarrollo del proyecto. Generan reconocimiento para actividades productivas tanto como para la gestión de los espacios, sus miembros requieren y buscan ingresos complementarios generados por fuera del taller productivo mediante la movilización de otros saberes y disponibilidades.

\section{El sentido de ser profesional}

La porosidad de la frontera entre el trabajo y el no trabajo aparece dentro de la opción militante como la posibilidad de realizar su labor de otra manera. Gabriel, graduado desde hace algunos años en diseño gráfico, ha encontrado en la portería un espacio en el que realizar una actividad remunerada. Sin embargo, le cuesta considerarla como un trabajo. Tal como se evidencia ante la solicitud de precisar en qué consiste el trabajo en la portería. Gabriel duda e intenta reformular el marco de referencia de la pregunta desplazándose desde el trabajo hacia la militancia:

Yo no veo como un trabajo... prefiero vivir con poca plata y hacer lo que me gusta...[...] después de mi último trabajo, fue muy desagradable, me echaron, entonces prefiero no ser ni empleado ni patrón [...] Ganas tiempo, podes elegir qué hacer. Trabajo en mi casa, y varía mucho a lo largo del año. "Trabajar sin patrón" no se trata solo de recuperar la plusvalía, como podríamos pensar. También es poder escuchar música o tomar mate en el lugar de trabajo. También es "contar" el CSC y formar parte de esta historia, ahí es cuando te das cuenta (Gabriel, 33 años, entrevista registrada en el CSC, agosto 2014).

En el testimonio de Gabriel, el trabajo consiste en aquello para lo que se formó en la universidad, diseño gráfico. Es el único miembro de su familia que realizó estudios universitarios. Como otros participantes del CSC, forma parte de una familia que 
apostó por los estudios universitarios, aunque esto no produjo la inserción profesional imaginada. La ruptura con el mercado de trabajo tradicional es un pasaje "desagradable" y de incertidumbre para Gabriel. En otro intercambio nos dirá algo más, que trabajando en una gran consultora se rehusó a colaborar en el diseño de una campaña de afiches publicitarios sobre la llegada del presidente norteamericano George W. Bush a la Argentina, en el marco de la Cumbre de las Américas. Se preguntaba para quién estaba trabajando, y ese cuestionamiento lo llevó a la situación de despido. Ese evento pone un límite ético-político en el ejercicio de su profesión. Un quiebre biográfico da lugar a que lo convoquen a formar parte del grupo de portería, a través de un familiar, y poco a poco comience a trabajar por su cuenta en su propio taller. Geneviève Pruvost (2013) señala el caso de quienes optan por la alternativa ecológica buscando un desarrollo en su oficio o actividad profesional como un camino gradual y móvil. Los intercambios que se observan en ese caso ponen en evidencia una continuidad entre trabajo doméstico, labor, obra, actividad profesional y militancia que caracteriza el involucramiento ecológico contemporáneo en estos espacios asociativos. El mismo se experimenta a partir del momento en el que se levanta el obstáculo presentado como material e ideológico que permite acceder a la "autoproducción".

Gabriel en su familia es el primero que expresa y logra la aspiración de acceder a la universidad. Su padre comerciante, su madre docente, tampoco cuentan con una trayectoria familiar de participación político-sindical o partidaria. Sí reconoce una profunda inmersión de su padre en el ámbito de los clubes deportivos barriales como formas de acción social. Formar parte de una generación colectiva movilizada también implica cuestionar el uso de su formación como universitario.

$\mathrm{Su}$ familia no posee una tradición militante, tampoco se ha involucrado en asociaciones estudiantiles durante su paso por la universidad en los años 90. La opción de romper con ese espacio laboral destaca un valor ético y político en el ejercicio profesio- 
nal. La actividad en la portería, con escasa remuneración, aparece como una solución temporaria que paulatinamente cobra mayor relevancia en cuanto posibilidad de formar parte de un colectivo humano, de su historia y de elegir la manera de ejercer su profesión. En efecto, sumarse al CSC lo vincula con un espacio que no funciona con la premisa que conoció en el mundo laboral de una gran consultora: le permite ejercer como diseñador gráfico en su domicilio en los horarios de su elección. También amplía el ejercicio profesional hacia el mundo asociativo, en el que trabaja en forma articulada con otros profesionales. Gabriel se acerca a su vez a una actividad militante en el seno de un colectivo cultural de intervenciones callejeras que funciona en el CSC. Vemos cómo la dimensión vocacional impregna tanto las actividades remuneradas como las no remuneradas. En el CSC convergen y se suman oportunidades de trabajo, por ejemplo, para diseñar una revista o la cobertura de un libro como un trabajo profesional remunerado. Posteriormente ofrecerá un taller de diseño, que reúne tanto sus competencias profesionales como su experiencia militante de arte callejero.

El amor por una actividad profesional aparece alimentado por el ambiente del medio asociativo, de autogestión, sin patrón, con música, con una gestión del tiempo flexible y el hecho de poder compartir esa experiencia en el relato colectivo. Como sus compañeros de la portería, pasa allí gran parte de su jornada laboral (entre 25 y 30 horas por semana), pero también realiza actividades expresivas y militantes en conjunto con agrupaciones que funcionan en ese espacio. En el proceso de relatar su trayectoria personal, esa articulación lo lleva a expresar otra cisión en su proyecto de vida personal que lo pone a resguardo de una situación que él caracteriza como un "cliché": una evaluación que refiere a "la pareja con dos niños, el perro y el auto".

La misma dinámica parece operar en la trayectoria de un joven chef profesional que se une a trabajar al grupo de cocina. Se acerca por invitación de uno de los miembros del CSC que, en este caso, ha conocido en el transcurso de su experiencia profe- 
sional. El chef apuesta por la autogestión para tener "más tiempo para él". En efecto, se encuentra en una etapa de excesivo trabajo y escasa remuneración, y considera que la actividad en el CSC le puede devolver mayor tiempo personal. La integración de un nuevo miembro se debate en el seno de la asamblea del taller productivo y se realiza si hay acuerdo, teniendo en cuenta el desarrollo de la actividad. Ese primer acercamiento se va ampliando paulatinamente, luego se muda con un camarada del CSC, lo cual le permite reducir los gastos de alquiler. Más tarde participará en un programa de radio, que no se vincula con su actividad profesional. También participa de la campaña por la expropiación del local y otras manifestaciones callejeras, tanto de carácter cultural como típicamente políticas ${ }^{17}$.

Durante ese período, la portería, la cocina y la cooperativa de consumo reciben a nuevos miembros, y muestran ese recorrido y esas prácticas. En otros espacios de menor dinamismo económico la incorporación de otras personas en los talleres genera mayor debate en las asambleas, por el riesgo de reducir los beneficios distribuidos. En efecto, la apertura a nuevos trabajadores no siempre se ve acompañada del aumento en la producción y exige la distribución de los mismos ingresos entre más miembros, en particular cuando los nuevos miembros no conocen el oficio y deben ser formados. Por esa razón, en el taller de costura algunas trabajadoras han abandonado el espacio.

Los intercambios y las dinámicas propias del CSC producen varios movimientos y desplazamientos. El chef que mencionamos recién comienza a participar activamente en manifestaciones propiamente políticas y participa en un programa de radio de carácter político. Del mismo modo, los distintos participantes se acercan a una actividad y luego conocen los talleres existentes y amplían su participación, ya sea en la cooperativa de consu-

17 Las agrupaciones políticas y estudiantiles convocan, por ejemplo, a marchar contra la invasión de Israel en la Franja de Gaza, ocurrida en agosto de ese año. 
mo o las demás actividades políticas y culturales. Esa manera de incorporar la actividad da cuenta, aparentemente, de modalidades de presencia cultivadas en torno a la autogestión, propias del conjunto de talleres que se realizan en el CSC, que rechaza una excesiva especialización entre quienes trabajan/producen/animan talleres y quienes requieren servicios/consumen/aprenden, o entre quienes realizan trabajo "frente a la máquina" y quienes gestionan y deciden los objetivos, así como la diferencia entre quienes proponen las actividades culturales y el público que forma parte de los asistentes habituales. De ese modo, la autogestión, que surge como una manera de organizar el trabajo, se extiende a otros ámbitos, a su vez que genera en quienes participan de esos procesos el reconocimiento de una nueva percepción de sí mismos. Si tomamos una expresión local de esa forma de presencia, escuchada entre nuestros interlocutores y plasmada en distintos comunicados de prensa, se trata de una manera de "habitar" el CSC. La consigna -y a su vez firma colectiva- «habitamos el CSC» antecede la lista de agrupaciones y cooperativas que funcionan en el Centro de La Plata desde 2012. Esa firma se repite a todo lo largo de la campaña desarrollada en favor del reconocimiento del CSC como entidad de utilidad pública, analizando -y en ese caso ampliando- los acuerdos entre los distintos miembros. Un desplazamiento que señala al ideal de autogestión de difícil realización, pero funcionando como un horizonte común, capaz de redefinir distintas prácticas de intercambio que integran la dimensión personal de realizar un modo de vida, una profesión, un involucramiento ético, estético y militante, y de orientar la organización en y de la acción en el seno del colectivo, a través de formas colaborativas que se instalan y se transforman a lo largo del tiempo como formas compartidas. Conviene analizar esta articulación, no exenta de tensiones, en el marco de un proceso en el que se instalan estructuras y gramáticas (Katz, 2011) de acción, más que como figuras estáticas en una posición predefinida. En ese sentido, "habitar" muestra una forma de articular las diferentes figuras que hacen del CSC un espacio compartido por estu- 
diantes, artistas, trabajadores, militantes y vecinos involucrados en distintos talleres de trabajo y de expresión.

\section{La cooperativa de consumo: trabajo vs. voluntariado}

La cooperativa de consumo comienza a funcionar en 2012 en un pequeño salón que permanecía vacante cerca del acceso al CSC. Se organiza en torno a un grupo de estudiantes de distintas carreras de la Facultad de Ciencias Económicas, que decide participar del programa de apoyo al voluntariado Amartya Sen. En una primera etapa participan del programa de voluntariado ${ }^{18}$ propuesto por la universidad, brindando acompañamiento a los pequeños productores rurales locales con distintas formas de apoyo técnico en los espacios de producción. Con una superficie de $9 \mathrm{~m}^{2}$ el espacio ubicado en la planta baja está abierto hacia el primer patio del CSC. El primer stock de compra fue adquirido con el fondo de apoyo al voluntariado promovido por el Ministerio de Educación, utilizado como una forma de capitalización. Sin embargo, los jóvenes expresan que la idea del voluntariado no forma parte de sus propios objetivos, orientados al cooperativismo. Por esa razón, no renuevan el programa de voluntariado y comienzan a producir recursos propios, por ejemplo mediante la selección y empaquetado de algunos productos que pueden comprar al por mayor ${ }^{19}$. En tanto cooperativa de consumidores,

\footnotetext{
18 Evocando al premio Nobel de economía, el programa otorga financiamiento a proyectos desarrollados por jóvenes universitarios que contribuyan a solucionar una necesidad local. El dispositivo limita el uso de dinero a la compra de materiales para llevar a cabo el proyecto y excluye el financiamiento de salarios. La ley 25.855 de promoción del voluntariado exige la realización de un acuerdo ante la organización y el voluntario para establecer derechos y obligaciones respectivas.

19 La mayoría de los productos que ofrecen los productores son alimentos con un modo de elaboración artesanal. También se ofrecen productos de higiene, textiles, publicaciones, etc. Regularmente, los miembros invitan a nuevos productores para ofrecer mayor variedad sin que se repitan los productos. Para el tercer año cuentan con 19 productores y 350 miembros, de los cuales alrededor de cien compran regularmente.
} 
el objetivo es ampliar el poder adquisitivo de los consumidores -entre los cuales se encuentra una buena cantidad de estudiantes que residen en la ciudad universitaria- y luego de los vecinos en general, acercando consumidores y pequeños productores.

Un cartel visible desde la entrada del CSC muestra el logo colorido de la cooperativa. Sobresale también porque la mayoría de los carteles que se colocan en el patio son consignas políticas y sociales, las paredes internas, como la fachada del CSC, muestran murales, posters y fotos de múltiples luchas y movilizaciones. Otra particularidad de la forma en que aspiran a desarrollar la cooperativa es la posibilidad de "salir a mostrar la cooperativa", generando actividades fuera del CSC, ya sea en la vereda, para interpelar a los vecinos del barrio, o bien participando en ferias realizadas en otros puntos de la ciudad que favorezcan la articulación con productores.

Las posibilidades de apertura o de "salir" con la cooperativa, si bien aparecen como un proyecto ampliamente valorado, implica revisar el equilibro entre la remuneración y el trabajo realizado, que pone en tensión el desarrollo de ese proyecto de la cooperativa y la continuidad de sus miembros a lo largo del tiempo. Por una parte, el voluntariado está asociado al riesgo del escaso involucramiento de los voluntarios, que "cae(n) en el proyecto cuando tienen tiempo". Nina Eliasoph lo muestra, por ejemplo, en su análisis del voluntariado americano: los voluntarios "a la carta", que ponen en riesgo el trabajo del mundo asociativo con estudiantes en distintas situaciones de vulnerabilidad por una presencia insuficiente, a corto plazo y por un involucramiento superficial que la autora define como un espíritu de "fun" (Eliasoph, 2011).

Por otra parte, la formalización de la actividad no parece ser una alternativa positiva: "si venis solo por la plata [me dice uno de los miembros] podés destruir todo". Según él, esa situación se ha dado con algunos miembros, que no se interesaron en el proceso organizativo de la cooperativa y se alejaron por la escasa remuneración recibida. Lo más importante es asegurar la presencia de 
organizadores involucrados en el proyecto y no que busquen simplemente resolver la cuestión de los ingresos. El involucramiento a lo largo del tiempo parece condicionado por la posibilidad o la imposibilidad de obtener un sostén personal por otros medios. En consecuencia, los miembros del CSC que muestran mayor presencia en sus distintos espacios incrementan la interacción con otros compañeros, participando en diferentes colectivos y actividades o solicitando sus servicios y apoyo profesional. Las cargas familiares son pocas o nulas (no tienen más de un hijo o hija a cargo) y cuentan con otras fuentes de ingresos. Una situación que da cuenta de las dificultades de sostener el compromiso por un largo plazo.

En 2013 la cooperativa atiende al público dos horas al día. De 19 a 21.00 horas un miembro se encarga de la apertura del local. Claudio está allí de lunes a viernes, registra las ventas de los distintos productos en un cuaderno diario, ofrece los productos disponibles, señala los próximos y busca generar pedidos para asegurar las nuevas compras. Situada en un lugar de paso dentro del CSC, la cooperativa se revela propicia para el intercambio con los transeúntes y la conversación sobre las actividades culturales en la ciudad, los seminarios, foros y meetings que se hacen en distintos centros culturales, las facultades y encuentros que se multiplican en el periodo electoral. De 19 a 20.00 horas suele ser calmo, Claudio alcanza a leer algunos apuntes y fotocopias de la Facultad de Ciencias Económicas, donde está realizando estudios en cooperativismo. A veces recibe la visita de algún familiar o amigo que conoce su rutina. Regularmente participa en la asamblea semanal del CSC, donde se coordina la gestión de la cooperativa del CSC y se trasladan las inquietudes y tensiones que van surgiendo ${ }^{20}$.

20 Mi presencia repetida en este espacio de tránsito favorece el encuentro de distintos participantes del CSC. Algunos consideran por un momento que formo parte de la organización, operando una inclusión tácita en el grupo que es rectificada en la medida en que presento la investigación en curso. 
Su remuneración es de 1.000 pesos por las diez horas semana$\mathrm{les}^{21}$, en parte financiada por un programa nacional del Ministerio de Trabajo, llamado de "apoyo a la autogestión"22, y en parte por la actividad misma de la cooperativa. Los primeros años Claudio es el único que obtiene ingresos de la actividad en la cooperativa. Otros desearían hacerlo y se ofrecen en la asamblea para incrementar las horas de atención al público, pero la escasa actividad del CSC por la mañana discontinúa la actividad. En agosto de 2013 la cooperativa enfrenta dificultades financieras y Claudio decide excepcionalmente donar sus ingresos del mes de julio, de escasa actividad por las vacaciones en el ciclo escolar. En un clima de incomodidad, la propuesta es aceptada por la asamblea. Como miembro, Claudio participa de la asamblea, busca productores que quieran ofrecer sus productos y quieran unirse a la cooperativa, pero esas horas dedicadas a la cooperativa no son contabilizadas en el cálculo de sus ingresos. Esa inestabilidad dará lugar a diversas conversaciones y propuestas en asamblea, para finalmente concluir en una nueva organización, aumentando la producción propia de la cooperativa, el envasado de productos comprados al por mayor y luego la incorporación de un servicio pago de reparto a domicilio. En 2014, varios miembros de la asamblea aseguran la presencia en el horario de venta y Claudio lo hace una vez por semana. Los otros días lo hacen los demás miembros, en forma rotativa. Su presencia en el CSC continúa siendo frecuente, ya que asiste a distintos cursos y actividades. A

\footnotetext{
21 En ese momento el salario mínimo está establecido en 4.400 pesos por un trabajo a tiempo completo. Para tomar un parámetro de consumo personal, el costo del pan es de 20 pesos el kilo. Los usos de los bienes y del dinero requieren una investigación específica basada en un registro detallado como el que propone la "etnocontabilidad" (Cottereau y Marzok, 2012). En la cooperativa el dinero es reinvertido para un mejor desarrollo de la actividad, como la compra de un freezer o de una bicicleta para realizar repartos domiciliarios. También, en tanto espacio de intercambio, la cooperativa -y el CSC en general- ofrece la posibilidad de intercambios no monetarios, como compartir un alquiler, servicio de internet, préstamo de bicicleta, etc.).

${ }^{22}$ Inicialmente pensado como un programa específico para las cooperativas de trabajadores, pero en la práctica se extiende a distintos ámbitos de la economía social.
} 
pesar de la menor responsabilidad de horarios, cuando termina sus actividades en el CSC pasa por la cooperativa, comparte un momento con sus camaradas y se intercambian las novedades. Si hace falta atiende al público, ya que es rápidamente identificado como parte de la cooperativa. Esta nueva organización ha permitido generar mayor participación de los miembros en la asamblea, ya que el manejo cotidiano de las actividades permite transformarse rápidamente en experto en ese espacio, contando con información específica que posee quien es responsable a su vez del consumo, de la producción y de la gestión.

Para Claudio es la consecuencia lógica: "cuando ves cómo funciona la cooperativa día a día, entendés y podes participar de la asamblea plenamente, si no, es sólo informativa". Esas palabras proponen una síntesis de la manera en que se tiende a organizar el trabajo en autogestión. La actividad productiva y las decisiones sobre la producción y el consumo se articulan y están abiertas a la participación de cada miembro presente en la asamblea. La distinción entre ambas se redefine permanentemente. Los precios de los productos son acordados con los productores, quienes a veces intercambian bienes. En ese espacio asociativo, la gestión del grupo exige una organización capaz de cuestionar las formas tradicionales de división del trabajo, entre trabajo operativo y toma de decisiones, $\mathrm{o}$, aun, entre el trabajo de los "trabajadores", "consumidores" y "universitarios". Con la nueva organización, una productora se encarga de la apertura de la cooperativa una vez por semana. Desde su acercamiento a la cooperativa como productora ha ampliado la cantidad de productos que ofrece (siempre en el rubro alimentación) y las modalidades de etiquetado y entrega de los mismos. Suele comprar en la cooperativa otros productos y también se ha incorporado en el reparto. La proximidad entre productores y consumidores a través del conocimiento mutuo genera ciertas capacidades para desafiar las formas tradicionales de división entre gestión, producción y consumo. Las trayectorias previas a la articulación dentro del CSC no dejan de tener incidencia en las maneras en que los distintos 
miembros se insertan en el colectivo; sin embargo, el registro etnográfico permite dar cuenta del hacer propio de la autogestión como un proceso en el que se constituyen nuevas trayectorias y modos de vida compartidos.

En efecto, en la cooperativa los productores se encuentran durante la semana para renovar sus producto y suelen aprovechar ese momento para abastecerse. En algunos casos incluso se intercambian productos directamente, en forma de trueque, sin pasar por la mediación de la cooperativa. Blanca me explica que, con su compañero, crearon una actividad llamada "Huerta simple", que consiste en cultivar allí donde vivimos. Blanca y su compañero buscan intervenir en distintos suelos para hacer demostraciones, dar consejos de aprovechamiento del terreno y crear dispositivos que faciliten la implementación de huertas en la ciudad. Los substratos que ofrecen en la cooperativa sirven para mejorar las condiciones de los suelos, de jardines o macetas para contribuir al desarrollo de las plantas. Una de las recomendaciones consiste en crear un huerto en espiral ascendente con plantas aromáticas. Esa forma favorece el aprovechamiento de agua y cada planta puede beneficiarse del intercambio con las otras. Un registro de campo muestra la interconexión entre la autogestión y modo de vida:

Blanca trae tres substratos. También trae limones y nos explica que los ha recogido esa misma mañana. En la cooperativa deja algunos para la venta y decide realizar un trueque con otra productora que ha llevado tortas. Para hacer el intercambio, los miembros de la cooperativa calculan informalmente una equivalencia monetaria (CSC, agosto 2014).

Ambas productoras poseen una trayectoria familiar similar. Tienen menos de 30 años, un hijo de corta edad y trabajan con sus compañeros de manera autogestiva. Sin embargo, en lo educativo, Blanca ha realizado estudios universitarios, aunque no los ha finalizado. Ambas viven en la periferia de la ciudad, pero Blanca 
está instalada en una zona histórica que posee un desarrollo urbanístico completo. Su colega se ha instalado en otro sector de ocupación más reciente, y las viviendas carecen de algunos servicios como asfalto y transporte público. Su modo de vida actual la ha llevado a cuestionar gran parte de las prácticas sociales establecidas. El valor de mercado de los productos opera como una referencia para establecer precios, pero no es el único elemento considerado. Para buena parte de los productores, compartir experiencias en la cooperativa forma parte de los elementos que llevan a participar del espacio, reivindicando saberes considerados de origen popular, que superen el consumismo de lo superfluo y dejen lugar a la emergencia de un discurso sobre buenas prácticas de intercambio y bienes comunes. Blanca argumenta que los limones que está ofreciendo son "un producto de la naturaleza y todos deberían poder beneficiarse". En efecto, está orgullosa de haberlos recolectado esa mañana, y los brinda como parte de la ofrenda de una naturaleza generosa. Por su parte, la otra joven productora está feliz de haber «cocinado para todo el mundo». Trae consigo un recipiente e irá repartiendo las tortas y budines en distintos lugares donde suele llevar sus productos.

Aunque el trueque no es habitual y los intercambios son generalmente monetarios, el intercambio de productos se extiende. Además de ofrecer e intercambiar, ambas compran lo que necesitan. Blanca señala que prefiere este tipo de espacios, porque "en el supermercado vas a comprar y es «una caja». No sé qué comprar cuando voy al supermercado". Cuando compra en la cooperativa o en algunos negocios cercanos a su casa conoce la historia de los alimentos, de donde vienen, quién los ha fabricado. Ese modo de vida atraviesa gran parte de los testimonios como una opción personal. Blanca me dirá luego, en su propia casa, que resulta una opción cuestionada por su familia. Sus padres, docentes, que solían colaborar desde la Patagonia para facilitar su estadía como estudiante en la ciudad de La Plata, dejaron de ayudarla cuando decidió ese cambio de rumbo. "Se preguntan cómo vivimos, lo que comemos, etc. Y es complejo de explicar lo que 
hacemos, además yo también me cuestiono". El cuestionamiento resulta de mayor envergadura cuando la opción por estos modos de vida comunes involucra la crianza de los niños bajo pautas no convencionales, en la alimentación, en las opciones de juegos y juguetes, de fabricación doméstica. La etnografía se ofrece entonces como un espacio reflexivo que invita a tomar distancia de sus propias prácticas.

La modalidad de involucramiento, que se pone en juego en particular en la transformación de los hábitos de consumo, puede comenzar en las compras agrupadas, el rechazo de ciertos productos de la dieta rioplatense $\mathrm{e}^{23}$, la adopción de productos "orgánicos", en el marco de formas de consumo compartidas, la fabricación y venta de productos caseros, el reciclado, el tejido y la confección artesanal, el encuadernado, la fabricación de libros con tapas artesanales, la edición y publicación de autores locales.

El acercamiento a la cooperativa de consumo muestra un proceso compuesto de afirmaciones y titubeos, de búsquedas y reflexiones, que se da tanto en la asamblea del grupo como en el intercambio con los participantes de distintas actividades del CSC, "ferias de productivos" generadas dentro como fuera de este espacio, en una red de socialización más amplia hacia modos de vida críticos compartidos.

\section{Reflexiones finales}

Las distintas formas de organizaciones colectivas que se hacen públicas durante la década de 2000, se vislumbran a través

\footnotetext{
23 Desde la antropología de la alimentación, Aguirre (2005) señala el creciente abandono de la dieta "rioplatense", basada en carne vacuna y compartida ampliamente por el conjunto de la sociedad hasta los años 80, en favor del desarrollo de modos de consumo alimenticio diferenciado por clases sociales. Allí la "comida sana" de los sectores de ingresos "altos" se articula con una comensalidad individual. En torno a la cooperativa de consumo vemos emerger formas de consumo de proximidad, que exceden el ámbito individual y familiar para extenderse dentro del ámbito asociativo.
} 
del trabajo etnográfico como el nacimiento a lo político de una generación que adquiere mayor protagonismo e intenta producir sus propias referencias y definiciones de lo político. Las particularidades del momento de emergencia y de movilización generalizada resultan de interés, más aún cuando las distintas organizaciones se van transformando a lo largo del tiempo y albergan en su interior distintas formas de involucramiento. Por un lado vemos los espacios de trabajo autogestivo, en los que la organización por asamblea surge como una arena para la toma de decisiones; pero también la autogestión implica abrir ese espacio a la participación de talleristas, que se apropian del espacio con actividades culturales, ferias, exposiciones y matinés.

El medio asociativo adopta formas particulares, tanto en las relaciones entre sus miembros como con las autoridades, desarrollando alianzas o disputando la legitimidad por los modos de intervención propuestos desde el Estado. Estas tensiones se hacen explícitas y se debaten, cuestionando evaluaciones sobre el trabajo justo, la remuneración adecuada, el arte de cómo desarrollar mejor la tarea, las formas de disciplina que se acuerdan y se intentan hacer cumplir en las sucesivas discusiones en asamblea, así como los cambios que se pueden introducir y en qué condiciones, para desarrollar una mayor autonomía. La participación a lo largo del tiempo permite identificar el espacio y el funcionamiento de la asamblea como el lugar de discusión y de efectivización de las decisiones, generalmente con una reiteración de las decisiones para lograr un funcionamiento acorde con los acuerdos propuestos.

El trabajo de campo en el CSC muestra a la autogestión como una apuesta de las clases populares -en un sentido amplio-, por la posibilidad de acceder a una participación en la gestión y en la toma de decisión de los distintos espacios. Si bien estos principios no logran siempre ser plasmados cabalmente, para desazón de sus propios participantes, generando tensiones entre miembros y en algunos casos la deserción de algunos de ellos, cuestionan públicamente los límites entre la experiencia de lo polí- 
tico y el trabajo, entre actividad militante y no militante, entre decisión personal y construcción colectiva de un modo de vida crítico compartido. Habitar el CSC excede aquí la evocación del ámbito doméstico en una forma de habitar en las calles mediante las campañas callejeras de reclamo de continuidad para el funcionamiento del CSC, en una alternativa al consumismo mediante ferias callejeras, tanto como en la búsqueda de la personalización de los espacios a través del arte.

El proceso de involucramiento es plural y multidimensional a partir de componentes propios del trabajo, del voluntariado, de la organización doméstica, de la actividad militante, entendida tanto en lo cultural, en lo social y en lo político. Esta dinámica da cuenta de la necesidad de revisar las conceptualizaciones que jerarquizan las manifestaciones por el reconocimiento de "derechos ciudadanos", por encima de las movilizaciones que se orientarían en defensa de derechos económicos y sociales considerados como propios de "intereses sectoriales". La etnografía se muestra capaz de dar lugar a expresiones de lo político acordes a estas prácticas emergentes, que se registran de acuerdo a las categorizaciones locales que exigen reconocer la dimensión política presente en distintos modos de involucramientos.

La dimensión vocacional se incorpora al trabajo en autogestion mediante el desarrollo conjunto de actividades habitualmente segmentadas en el proceso productivo. En el desarrollo profesional (aprender un oficio, la gestión cotidiana de una actividad, valorizar el conocimiento a través de la enseñanza), en la gestión del tiempo (permeable a elegir los horarios en función de las necesidades del trabajador, tomar mate o escuchar música en el lugar de trabajo), pero también en función del desarrollo personal (aprendiendo artes callejeros, danzas, radio o cocina) se ve la estructuración de un modo de vida compartido. El cruce de estas actividades en un mismo ámbito permite desplazamientos en distintos sentidos, desde el modo de ejercer la profesión hacia espacios de militancia (como es el caso de Gabriel) o, inversamente, para los jóvenes estudiantes que se acercan al CSC a partir de una trayectoria militante (como 
Héctor) y encuentran una actividad remunerada o de ocio. La copresencia de esas actividades contribuye a un proceso de ampliación, aunque no siempre posible de sostener en el tiempo, sobre todo en las experiencias en donde prevalece la actividad laboral como eje central. La edad de los miembros y el hecho de tener o no hijos a cargo abre la posibilidad de un cuestionamiento, por ejemplo de los familiares. La relación con los niños como límite en las experiencias aceptables también se da en sentido contrario, facilita en los compañeros del CSC la justificación de un alejamiento del modo de vida alternativo hacia el "cliché" de la familia de dos adultos, dos niños, un perro y un auto. En efecto, lo vemos en la cooperativa de consumo como una recurrencia de abandono del espacio, justificada por quienes continúan en el espacio colectivo pero no tienen hijos pequeños a cargo.

Integrar en el análisis la experiencia del medio asociativo a lo largo del tiempo, sus tensiones con el mundo político pero también con la esfera familiar común, esforzándose en distinguir los titubeos, las dudas, los procesos de evaluación realizados por los propios protagonistas como modo de involucramiento, permite dar cuenta, mediante la reflexión etnográfica, de modos de vida críticos, a la vez que renovar el cuestionamiento sociológico de formas de coordinación y de coconstrucción plurales que, en el curso de las interacciones, comienzan a aparecer como formas de vida compartidas. Registrar estos procesos etnográficamente permite mostrar la emergencia de formas de lo político articuladas al trabajo, al arte, al consumo, que potencialmente acceden a una mayor visibilidad y a una mayor estabilidad. Una estabilidad que no se entiende como la consolidación de una forma de entender lo político, sino que aparece como la evaluación continua de las formas en que lo político se hace presente en lo cotidiano.

\section{Referencias}

Aguirre, P. (2005). Estrategias de consumo: ¿qué comen los argentinos que comen? Ciapp-Miño y Dávila. 
Arendt, H. (1983). Condition de l'homme moderne. París: Éditions Calmann-Lévy.

Breviglieri, M. \& Pattaroni, L. (2005). Le souci de propriété. Vie privée et déclin du militantisme dans un squat genevois, dans Bernard H. y A. Morel (dir.), La Société des voisins. Partager un habitat collectif ( pp. 275-289). París: Éditions de la Maison des sciences de l'Homme.

Casimiro, D. (2014). Enquête artistique sur les années de plomb en Argentine. América, 44. Recuperado de: http://america.revues.org/663.

Calvès, A.-E. (2009). Empowerment: généalogie d'un concept clé du discours contemporain sur le développement. Revue Tiers Monde, 4(200), 735-749.

Cefaï, D. (1996). La construction des problèmes publics. Définitions de situations dans des arènes publiques. Réseaux, 14(75), 43-66.

Cottereau, A. (2004). La désincorporation des métiers et leur transformation en "publics intermédiaires": Lyon et Elbeuf, 17901815, en Kaplan, S. L. y P. Minard (dir.), La France, malade du corporatisme? XVIII e-XX e siècles (pp. 97-145). París: Éditions Belin.

Cottereau, A. \& Marzok M. (2012). Une Famille andalouse. Ethnocomptabilité d'une économie invisible. París : Éditions Bouchene.

Cross, C. (2010). El empleo como aspiración y la precariedad como práctica: Experiencias de trabajadoras de una planta social de clasificación de residuos. VI Jornadas de Sociología de la UNLP, 9 y 10 de diciembre de 2010, La Plata, Argentina. En Memoria Académica. Recuperado de: http:/ / www.memoria. fahce.unlp.edu.ar/trab_eventos/ev.5384/ev.5384.pdf

Cross, C. (2014). Organizarse, trabajar y luchar: políticas sociales focalizadas y la construcción de capacidades colectivas en una organización territorial de Buenos Aires. Memorias, 12(21), 55-72.

Cunha Comerfod, J. (1999). Fazendo a Luta. NAUP: Relume-Dumara.

Delamata, G. \& Armesto, M. (2005). Construyendo pluralismo territorial. Las organizaciones de desocupados del Gran Buenos Aires en la perspectiva de sus bases locales, en G. Delamata (dir.), Ciudadanía y territorio. Las relaciones políticas de las nuevas identidades sociales (pp. 105-155). Buenos Aires: Esitoria Espacio. 
Díaz, P. y Rius, P.-V. (2017). Engagements personnels dans des causes publiques. Les "travailleurs desocupados" en Argentine et les parents des disparus au Chili. Anthropologie E développement, (en prensa).

Di Marco, G. (2007). Justice sociale et droit lié au genre. Revue internationale des sciences sociales, 1(191), 51-74.

Di Stefano, R., Sábato, H., Romero, L. y Moreno, J.-L. (2002). De las Cofradías a las Organizaciones de la Sociedad Civil. Historia de la iniciativa asociativa en Argentina (1776-1990). Buenos Aires: Editora Gadis.

Eliasoph, N. (2011). Making Volunteers: Civic Life after Welfare's End. Princeton y Oxford: Princeton University Press.

Gaudichaud, F. (2012). El volcán latinoamericano. Izquierdas, movimientos sociales y neoliberalismo. Concepción: Editora Escaparate.

González Bombal, I. (1987). Derechos humanos: la fuerza del acontecimiento, en E. Verón et al. (dir.), Discurso político. Lenguajes y acontecimientos (pp. 145-166). Buenos Aires: Editora Hachette.

Grimberg, M., Fernández Álvarez, M., Carvalho, R. (eds.). (2009). Estado y movimientos sociales: estudios etnográficos en Argentina y Brasil. Buenos Aires: Antropofagia.

Hély, M. (2009). Les Métamorphoses du monde associatif. Paris: Presses universitaires de France.

Katz, J. (2011). Se cuisiner un statut. Des noms aux verbes dans l'étude de la stratification sociale. Ethnografiques Analyser les présences au travail: visibilités et invisibilités, 23. Recuperado de http:/ / www.ethnographiques.org/2011/Katz - consultado el 28.03.2018

Manzano, V. (2004). Tradiciones asociativas, políticas estatales y modalidades de acción colectiva: análisis de una organización piquetera. Intersecciones en Antropología, 5, 153-166.

Mazzeo, M. (2007). Poder popular. Buenos Aires: Editora El Colectivo.

Merklen, D. (2005). Pobres ciudadanos. Buenos Aires: Ed. Gorla.

Pruvost, G. (2013). L'alternative écologique. Terrain, 60. Recuperado de http:/ / terrain.revues.org/15068.

Quattrocchi-Woisson, D. (2003). Argentine, enjeux et racines d'une société en crise. Paris: Éditions Tiempo / Éditions du Félin. 
Quijoux, M. (2011). Néolibéralisme et autogestion. L'expérience argentine. París: Ed. IHEAL.

Quiros, J. (2011). El porqué de los que van. Peronistas y piqueteros en el Gran Buenos Aires (una antropología de la política vivida). Buenos Aires: Antropofagia.

Rius, P.-V. (2014). Crise du travail et redéfinition des frontières du social en Argentine à travers le prisme de la mobilisation des desocupados. Travail et Emploi, 138. Recuperado de https://travailemploi.revues.org/6363.

Rius, P.-V. (2010). Faire valoir sa légitimité. Radicalité et banalité des mouvements de desocupados en Argentine des années 1990 à 2007. Thèse de doctorat en sociologie, École des Hautes Études en Sciences Sociales, Lille ANRT.

Rosato, A. y Balbi, F. (Eds.). (2003). Representaciones sociales y procesos políticos. Estudios desde la antropología social. Buenos Aires: Antropofagia.

Simonet, M. (2007). Entre emploi et bénévolat, le volontariat associatif. Connaissance de l'emploi, 45.

Svampa, M. (Dir.). (2000). Desde abajo. La transformación de las identidades sociales. Buenos Aires: Biblos-UNGS.

Thévenot, L. (2016). La acción en plural. Una introducción a la sociología pragmática. Buenos Aires: Siglo XXI. 